\title{
Why Balloons Make a Loud Noise When They Pop
}

\author{
Edward Ross \\ San Jose Unified School District Home Study Program, San Jose, CA, PO Box 8, Moffett Field, CA 94035, USA.
}

Jayanta Panda, James C. Ross and Laura K. Kushner
NASA Ames Research Center, MS 260-1, Moffett Field, CA 94035, USA.

(Received 15 September 2017; accepted 10 June 2019)

Measurements of balloon loudness and pressure signatures are presented for a variety of balloon shapes. The loudness and recordings were made 3.2 meters from the popped balloons. The balloons were of 3 types: round, long, and extremely long (the same type that is used to make balloon animals), filled with 3 gases, and inflated to multiple sizes. The data indicates that all 3 types of latex balloons share similar peak frequencies and acoustic signatures in spite of differences in shape and diameter or length when inflated. The data also shows a correlation of loudness to the ratio of specific heats of the gas and inflated diameter of the balloons. The data does not support some of the common hypotheses of balloon popping noise generation. It appears that the sound is generated by the vibration of the balloon surface and the ruptured edge of the latex. This explanation is consistent with the current acoustic measurements and shadowgraph videos, and the hypothesis of Pätynen, et al. ${ }^{4}$

\section{INTRODUCTION}

Several years ago, the first author was cleaning up after a party — popping many balloons. Some were filled with helium and others with air. He noticed that the helium balloons seemed to pop with a louder sound than the air-filled balloons. This led to a series of experiments to see if this was true. In general, for round balloons, he found that air was louder. However, for long balloons, helium was louder. In order to find out the reason for these mixed results, a better understanding of the physics behind the noise generated by popped balloons was needed.

In researching balloon-popping physics, we found conflicting explanations of why balloons make noise when they are popped. Murphy and Doherty ${ }^{1}$ suggest that the noise is caused by the gas, which is under pressure in the balloon, expanding rapidly and creating an expanding pressure wave. Murphy and Doherty state that, "... When the air that was inside the balloon reaches atmospheric pressure, it's still rushing outward. It overshoots, creating a lower pressure region where the balloon used to be. So then, the air rushes back to fill that lower pressure area. This creates an expansion wave of low pressure, which follows the compression wave. This alternation of compression and expansion makes a sound with a given pitch. Of course, it doesn't stop there. The air rushes back, overshoots, then rushes out, overshoots, and so on, getting a little closer to equilibrium each time. Depending on the size and initial pressure in the balloon, the oscillation between compression and expansion takes different times. That's why popping different balloons produces different pitches." 1 Marder et $\mathrm{al}^{2}$ suggest that the noise is an artifact of the balloon latex ripping faster than the speed of sound. Additionally, Barbut ${ }^{3}$ suggested that, instead of the sudden expansion of the compressed gas or a "sonic boom" formed by the supersonic motion of the ripped latex, the sound is generated by a vibration of the latex surface similar to a drum. Barbut states that, "The sound comes from a wave propagating through the balloon skin as it pops - it's acting like a drum skin, essentially. The strain energy stored in the rubber is being converted to sound energy." 3 Little ex- perimental data is presented in these three reports to back up the different hypotheses. Instead, these three reports present logical sounding discussions. While references 1-3 are not in the technical literature, they present the most common explanations of the physical source of balloon noise.

References 4-6 present the spectral data and noise directivity of popped balloons, but no explanation of the physics of the noise production is provided. Pätynen et $\mathrm{al}^{4}$ determined the directionality of balloon noise for acoustic testing applications. Similarly, Horvat et $\mathrm{al}^{5}$ compared the sound pressure level (SPL) and frequency content of balloons to other methods of generating noise for acoustic testing, such as blank pistols and firecrackers. Chéenne et $\mathrm{al}^{6}$ attempted to determine if balloon size and inflation pressure affected the SPL of balloon pops, or the frequency content. Additionally, Moulinet and Adda-Bedia ${ }^{7}$ described the fragmentation patterns of balloons, but do not comment on its relevance to the sound made by a popped balloon or the mechanism.

The current study was motivated by the lack of a clear explanation of the reason for the popping sound. The goal was a comparative study of the character of the sound generated by popping different types of balloons filled with one of three different gases. The study would then be used to establish a clearer understanding of the physics of noise generation. The first author presented these expanded results at the 2014 Synopsis Science and Technology Championship and at the 2014 California State Science Fair.

\section{EXPERIMENTAL SETUP AND PROCEDURE}

Our experiment involved measuring both the loudness and waveform of sound generated upon popping a variety of balloon types that were filled with various inflation gases. We popped three types of balloons filled with helium (He), air, or tetrafluoroethane (R-134A). Table 1 shows the balloon types and sizes when inflated (hereafter called inflation diameter or length) at which the balloons were popped. To our knowledge, no other study has compared the noise produced by balloons 


Table 1. Summary of balloons tested.
\begin{tabular}{|c|c|c|}
\hline $\begin{array}{c}\mid \begin{array}{c}\text { Balloon } \\
\text { Type }\end{array} \\
\text { Inflation Diameter } \\
\text { or Length, cm }\end{array}$ & $\begin{array}{c}\text { Inflation } \\
\text { gas }\end{array}$ \\
\hline \hline Round 9" & Diameter - 15.2, 21.5 & Helium, Air, \\
& & R-134A \\
\hline Long & Diameter - 10 & Helium, Air, \\
& Length $-30-33,41$ & R-134A \\
\hline Long Skinny & Diameter - 10 & Helium, Air, \\
("animal") balloons & Length $-\sim 130$ & R-134A \\
\hline
\end{tabular}

Table 2. Gas properties.

\begin{tabular}{|c|c|c|}
\hline Gas & Density, $\mathrm{kg} / \mathrm{m}^{3}$ & Ratio of Specific Heats, $\gamma$ \\
\hline \hline Helium & 0.18 & 1.6 \\
\hline Air & 1.23 & 1.4 \\
\hline R-134A & 4.25 & 1.1 \\
\hline
\end{tabular}

filled with different gases.

In addition to round balloons, long and long skinny balloons (the kind used to make balloon animals, henceforth referred to as animal balloons) were tested in order to determine if the peak pop frequency of balloons depends on the inflation diameter, balloon geometry, or the natural vibrating frequency of the latex.

The gases were originally chosen because they had different densities. However, as it turned out, they also had different specific heat ratios, $\gamma$. Table 2 shows the properties of the three gases. ${ }^{8-10}$ Compressed air was generated using a shop air compressor. The helium was obtained at a local party store. The $\mathrm{R}-134 \mathrm{~A}$ was purchased at an office supply store where it was sold as a compressed-gas cleaning duster.

Initially, a selection was made for a balloon type and inflation diameter. For example, round balloons were inflated to a $21.5 \mathrm{~cm}$ diameter. For each combination of balloon geometry, inflation diameter (length for long balloons), and gas, ten samples were recorded. All of the balloons used in this experiment were made by the same manufacturer and were purchased at the same time. To avoid possible differences in the latex properties, all of the round balloons were chosen to be white. The long and animal balloons were only available in multiple colours, so an equal number of several colours were included in each group of ten of these balloon types. For a given test case, balloon inflation diameter was kept constant. Since the tension in the latex membrane is directly related to the balloon inflation diameter, it was expected that the balloons of the same diameter would have the same gas pressure. Additionally, the balloons and gas containers were outside $30-40$ minutes before testing began to acclimate them to the testing environment.

Figure 1 shows a schematic of the test setup for measuring the balloon noise. The balloons were always popped at $\sim 76 \mathrm{~cm}$ above the ground. The microphone and sound level meter were also located $76 \mathrm{~cm}$ above the ground. The balloons were popped by hand using a pin that was $\sim 45^{\circ}$ off of the direct path to the instrumentation. We recorded the sound from the balloon pops using Audacity ${ }^{\circledR 11}$ software and a Shure SM57-LC microphone connected to a laptop computer through a Roland Micro-Cube N225 amplifier. The manufacturer's specifications for the microphone indicate $\mathrm{a}-2$ to $0 \mathrm{~dB}$ deviation in response from $200 \mathrm{~Hz}$ to $3 \mathrm{kHz}$ with higher deviations above $3 \mathrm{kHz}$. The data were acquired at $44.1 \mathrm{kHz}$.

A Radio Shack ${ }^{\circledR}$ model 33-2055 sound level meter was used to measure the overall loudness of the balloons (Aweighted, fast response, peak hold) simultaneously with the

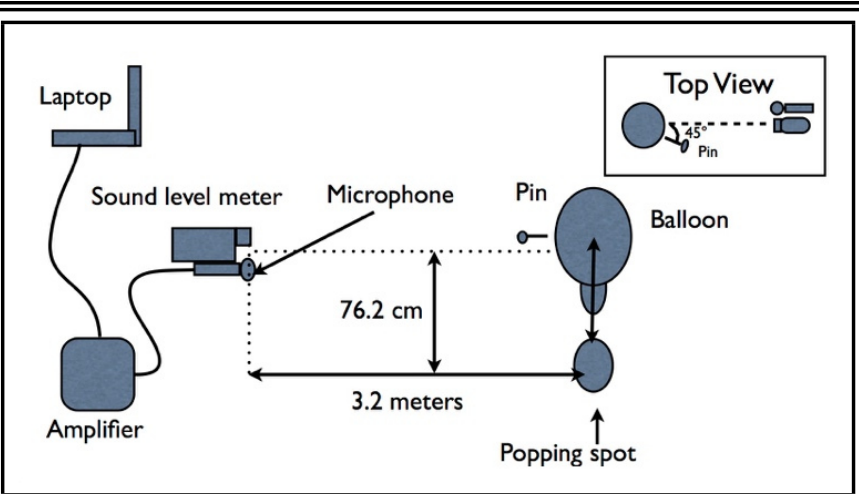

Figure 1. Test setup for measuring loudness and waveforms of popped balloons.

sound recordings. Ten measurements were made for each balloon type, inflation diameter, gas, and measuring distance combination.

One goal of the experiment was to measure perceivable differences in loudness between balloons filled with different gases, so A-weighting was applied to the sound-level measurements. We acknowledged that A-weighting may have suppressed contribution from frequencies below $1 \mathrm{kHz}$. However, the effect was uniform for all data presented here. Since comparisons of the loudness (A-weighted) and spectra (not weighted) for the different balloons and gases were all made using the same process, the conclusions drawn should be valid.

Spectra were averaged for 10 pops of a particular balloon type, gas, and inflation diameter. FFT analysis was performed with the Audacity ${ }^{\circledR}$ software using a Hanning window and 2048 sample records resulting in a frequency resolution of $21.5 \mathrm{~Hz}$. The loudness results were averaged over the same 10 measurements made using the sound level meter.

The pressure in two round balloons was measured as a function of diameter using a simple u-tube water manometer. Two balloons were inflated to a given diameter while connected to the manometer so the readings could be made quickly. The balloons were never allowed to deflate during the measurement process. The measurement was repeated for a number of diameters. These results are shown in the Experimental Results section below.

Figure 2 shows an expanded view of a typical time history of a balloon pop. Unlike impulses from a gunshot, ${ }^{12}$ balloonpopping sounds are rapid oscillations that increase and decrease in amplitude. The primary feature is a fast-growing sound packet that peaks after $\sim 5 \mathrm{~ms}$ from the start of the pop, and then decays to long lasting, relatively low amplitude fluctuations. In addition to the directly radiated component, there are multiple reflections from the surrounding. We hoped that the grass would reduce the reflection from the ground, which seemed to be the case. However, a reflection from a fence ( $\sim 2 \mathrm{~m}$ to one side of the measurement station) was seen in most of the waveforms. A second reflection (delayed 0.035 seconds) was from the side of the house, about $5 \mathrm{~m}$ to the side opposite the fence. The background noise levels tended to be $45 \mathrm{~dB}$ or lower, and the quietest balloon measured reached $65 \mathrm{~dB}$.

The effect of the reflected waves on the sound measurements needs to be discussed. The transient nature of the sound-packet makes the reflected packets appear at different times, which reduces the potential of interference between them. Since the entire time trace was used to calculate the overall levels and 


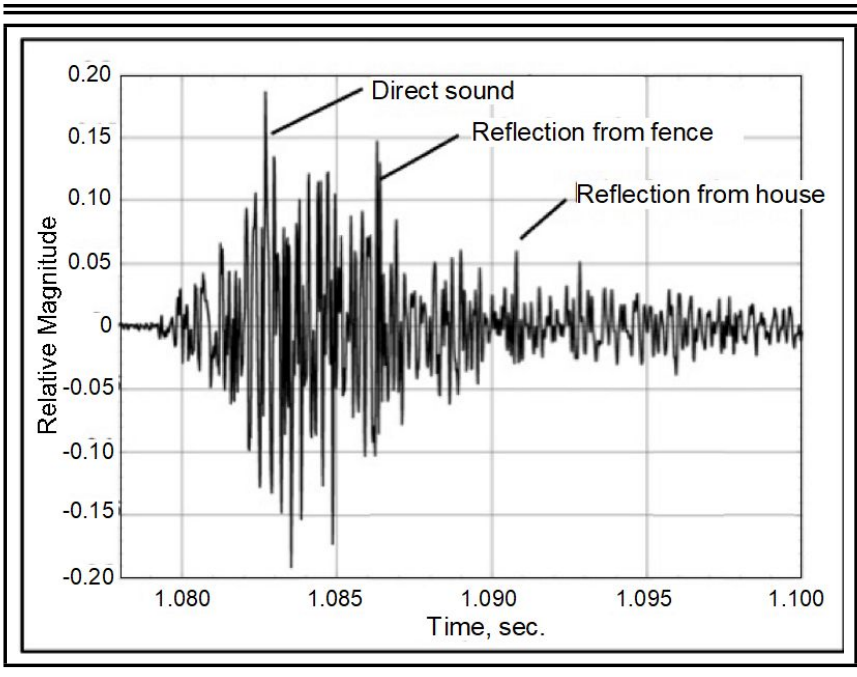

Figure 2. Microphone level-time trace for a long balloon filled to $41 \mathrm{~cm}$ length with air — screen shot from Audacity ${ }^{\circledR}$.

the spectral amplitudes, the measured numbers are higher than the directly radiated component; albeit the spectral shape was expected to be relatively unaffected.

Finally, all balloons were tested in the same setup, hence the impact of reflection was identical for all test cases. As mentioned earlier the goal of the present work was a comparative study of the sound generation, rather than an absolute measurement of the sound levels. Pätynen, et al. ${ }^{4}$ and Chéenne, et al. ${ }^{6}$ reported similar time-histories. However, those time-histories did not include echoes, as those tests were conducted in an anechoic chamber. Comparison with the data presented in these references will be made in the following section. They also recorded some slow-motion videos of balloons pops that are similar to our shadowgraph videos. Additionally, they found a correlation between balloon size and low frequency resonances.

We also recorded high-speed shadowgraph videos to visualize balloon pops in detail. The shadowgraph photography was performed at the NASA Ames Research Center next to the test section of the 9-by7-Foot Wind Tunnel. Videos were recorded of the round and extra long balloons with the three test gases at 20,000 frames/second. It should be noted that NASA did not financially support this research.

Sound recording data was acquired over a period of about 3 months. On a given day, data was acquired, at a minimum, for 10 repetitions with all three gases, a given balloon type, and inflation diameter. This was done to reduce the effect of uncontrolled variables (e.g. temperature) and to allow meaningful comparison of the effect of the inflation gas on loudness and on the waveform for a particular balloon type and inflation size. In this way, the potential changes in the noise due to the inflation gas would be more accurately discerned.

\section{EXPERIMENTAL RESULTS}

Figures 3, 4, 5 show typical spectra generated by the three different balloon types. The first important observation was that the R-134A filled balloons were the loudest for all cases except the long balloons. For long balloons, all gases produced approximately the same loudness. Air was usually the second loudest but relatively close to helium. Animal balloons filled with helium were the quietest. All long balloons had relatively small loudness differences between the three gases. All

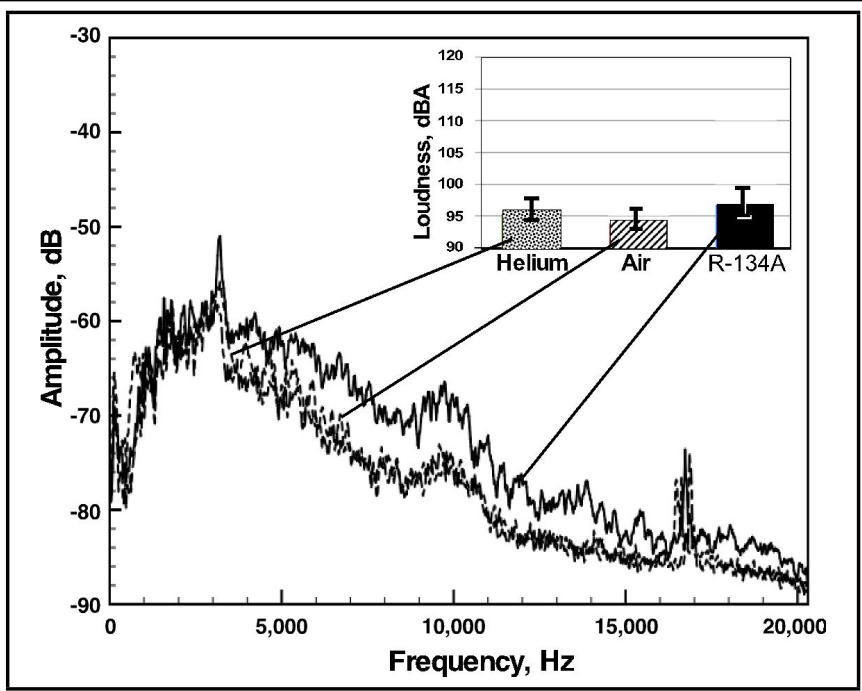

Figure 3. Spectra generated by popping long balloons inflated to $21.5 \mathrm{~cm}$ length with helium, air, and R-134A.

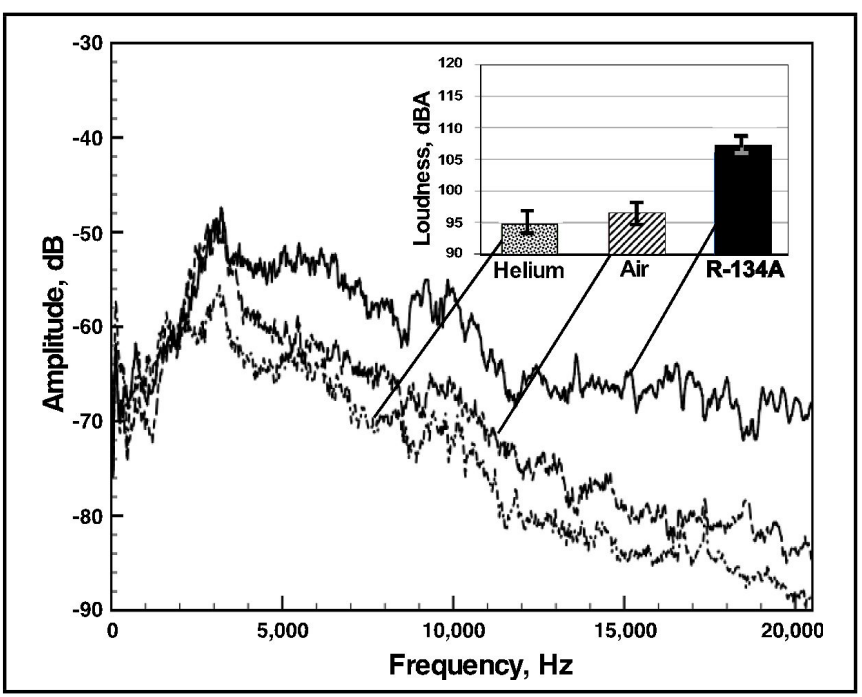

Figure 4. Spectra generated by popping round balloons inflated to $33 \mathrm{~cm}$ diameter with helium, air, and R-134A. The inset bars show the A-weighted overall level.

balloons were louder when inflated more. A remarkable feature of figures $3,4,5$ is that the spectral peaks occur within a frequency band of $3,100-3,400 \mathrm{~Hz}$ that is independent of the balloon shape and gas. Pätynen, et al. ${ }^{4}$ and Chéenne, et al. ${ }^{6}$ also reported the presence of a dominant frequency near $3 \mathrm{kHz}$. This suggests that the main mechanism of sound is independent of inflation gas, balloon shape and inflation diameter/length.

There were some minor differences in the spectral shapes among various balloons. The spectral energy for the R-134A filled balloons above $3000 \mathrm{~Hz}$ was always higher than that for the other gases. Below $3000 \mathrm{~Hz}$, helium was the loudest for a minority of cases. No pattern of balloon type or inflation level could be determined for helium being occasionally louder at low frequencies.

The balloon pressure was relatively low for all balloon types. The variation in pressure for a round balloon versus inflation diameter is shown in Figure 6. The balloon pressure initially decreases with increasing diameter, in this case reaching a minimum at about $17 \mathrm{~cm}$. As the balloon is inflated further, the pressure begins to rise rapidly. This is a result of the mate- 


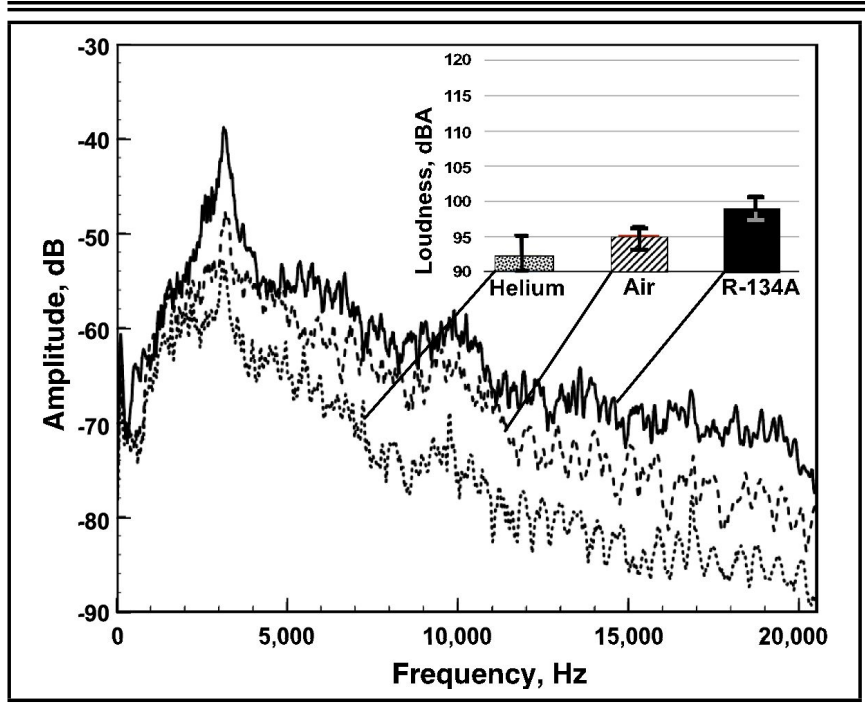

Figure 5. Spectra generated by popping animal balloons, fully inflated to $130 \mathrm{~cm}$ length with helium, air, and R-134A.

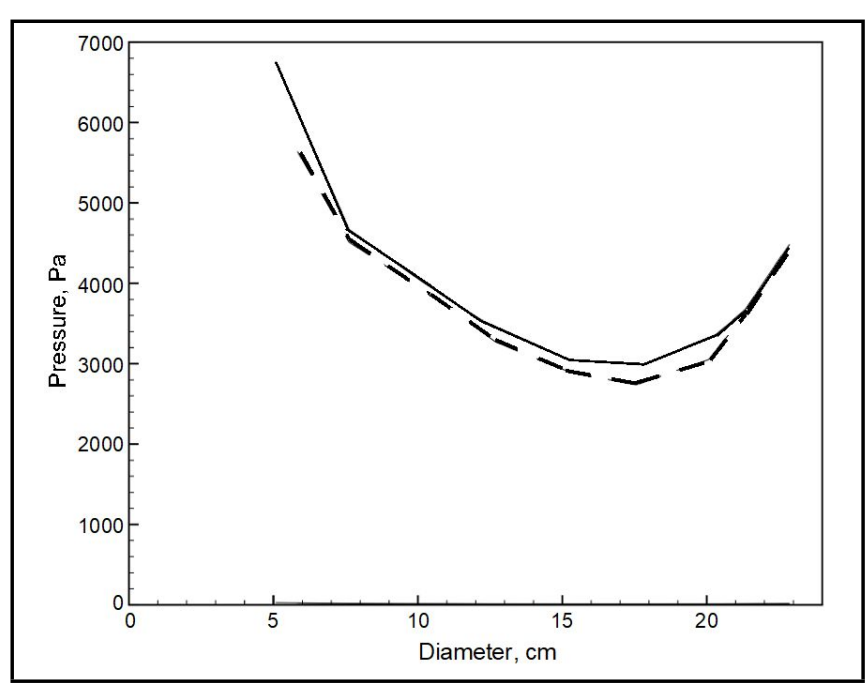

Figure 6. Variation in pressure with inflation diameter for two round balloons.

rial properties of latex. The stress-strain curve initially has a steep slope that flattens significantly, with little change in stress from about $100 \%$ to $500 \%$ strain, after which the slope increases again to the failure point at more than $700 \%$ strain. $^{13}$ At the gas pressures in the popped balloons, the enclosed gas is compressed in volume by $\sim 3.5 \%$ relative to its volume at atmospheric pressure.

A major difference between the present data and those of Pätynen, et $\mathrm{al}^{4}{ }^{4}$ is that the latter shows spectra with much higher energy between $250 \mathrm{~Hz}$ and $800 \mathrm{~Hz}$, as well as a correlation between balloon size and low frequency resonances. We saw low frequency resonances of $\sim 500 \mathrm{~Hz}$ for the round balloons and $\sim 220 \mathrm{~Hz}$ for the long balloons but at much lower amplitudes. We also did not see a change in frequency for the round balloons from $15.2 \mathrm{~cm}$ and $25.1 \mathrm{~cm}$ inflation diameters nor with increased inflation length of the long balloons. The exact reason for the differences could not be determined. There were multiple differences in the experimental setup between the present work and that reported in Pätynen, et al, ${ }^{4}$ such as the shape of the balloons, extent of stretching, method of holding and popping, and use of an anechoic chamber; all of which could have contributed to the low-frequency differences.

Further insights into the generation mechanisms are found
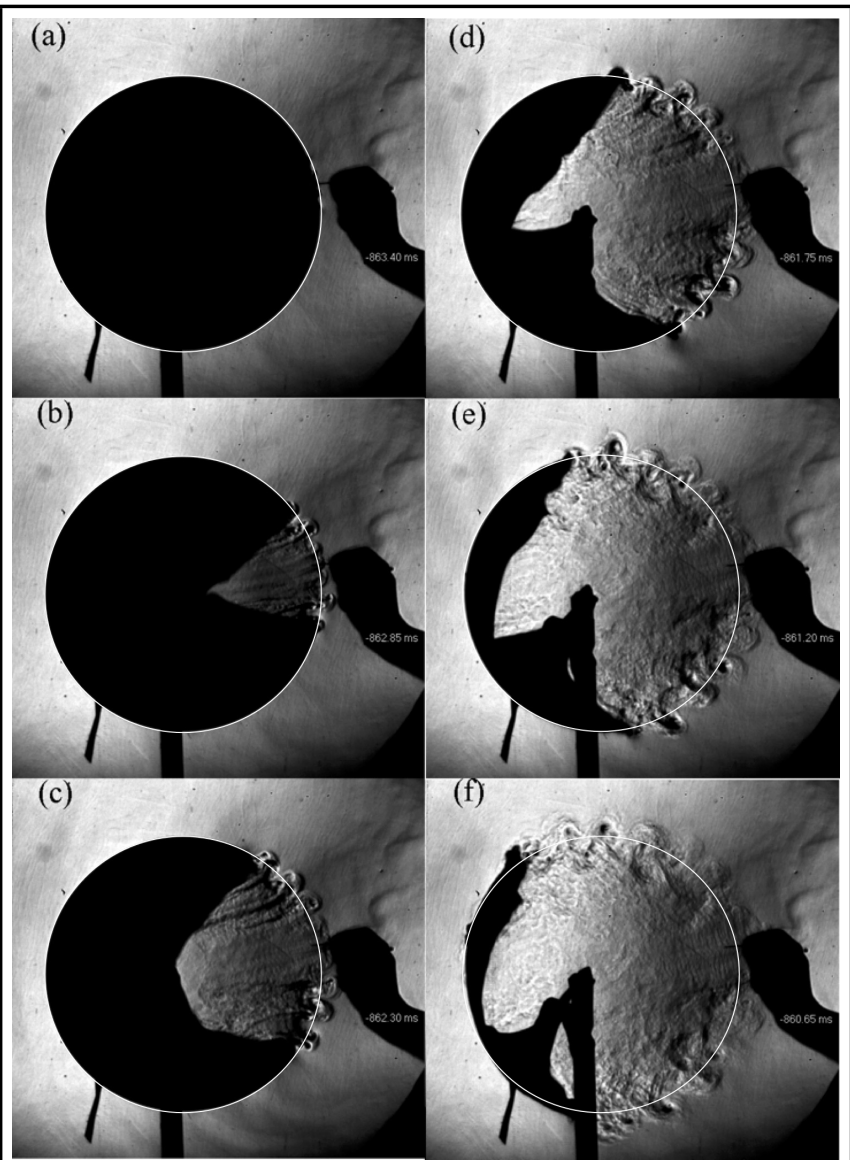

(f)

Figure 7. A sequence of shadowgraph images of a round air-filled balloon, isolated from the high-speed shadowgraph video (.mp4 file available, $5 \mathrm{MB}$ ), showing the expansion of the compressed gas and the recession of the balloon skin; time interval between consecutive frames is $0.55 \mathrm{~ms}$.

from shadowgraph videos. These videos show that pressure waves are shed from the latex surface and at the ripped edges as they ripple and pull away from the breach in the surface. Frames shown in figures 7 and 8 are extracted from the highspeed video. Figure 7 shows progression of the overall bursting process. The pin-prick initiates a rapidly propagating tear in the latex surface and release of the trapped gas. The edges of the tear oscillate as they retreat from the breach, creating ripples on the stretched skin of the balloon at its natural frequency. The mushroom-shaped vortical structures are formed by the flapping and retreating edges of the ruptured latex. Close inspection of the video frames show ripples in the undamaged latex near the breach that appear to be the source of the surface vibrations. These are also likely at the natural frequency of the stretched latex. The white circles in the video frames indicate the undisturbed surface of the balloon before it is popped.

The video frames of Figures $7 \mathrm{a}-\mathrm{f}$ are at a time interval of $0.55 \mathrm{~ms}$. Figures 8a-f are a similar series of frames acquired at intervals of $0.1 \mathrm{~ms}$ starting partway through the rupture process. The shorter time interval allows for a scrutiny of the nascent sound waves emanating from the burst. The first observation is that the sound waves are not associated with the individual mushroom-shaped vortices. The compression wave at the lip of the ruptured skin is attached to the skin, not to the emerging vortex. Additional insight into the sound sources comes from a closer look into the compression front of a sound wave shown in figure 8 . An examination of the photos shows spatially periodic compression and expansion regions emanat- 


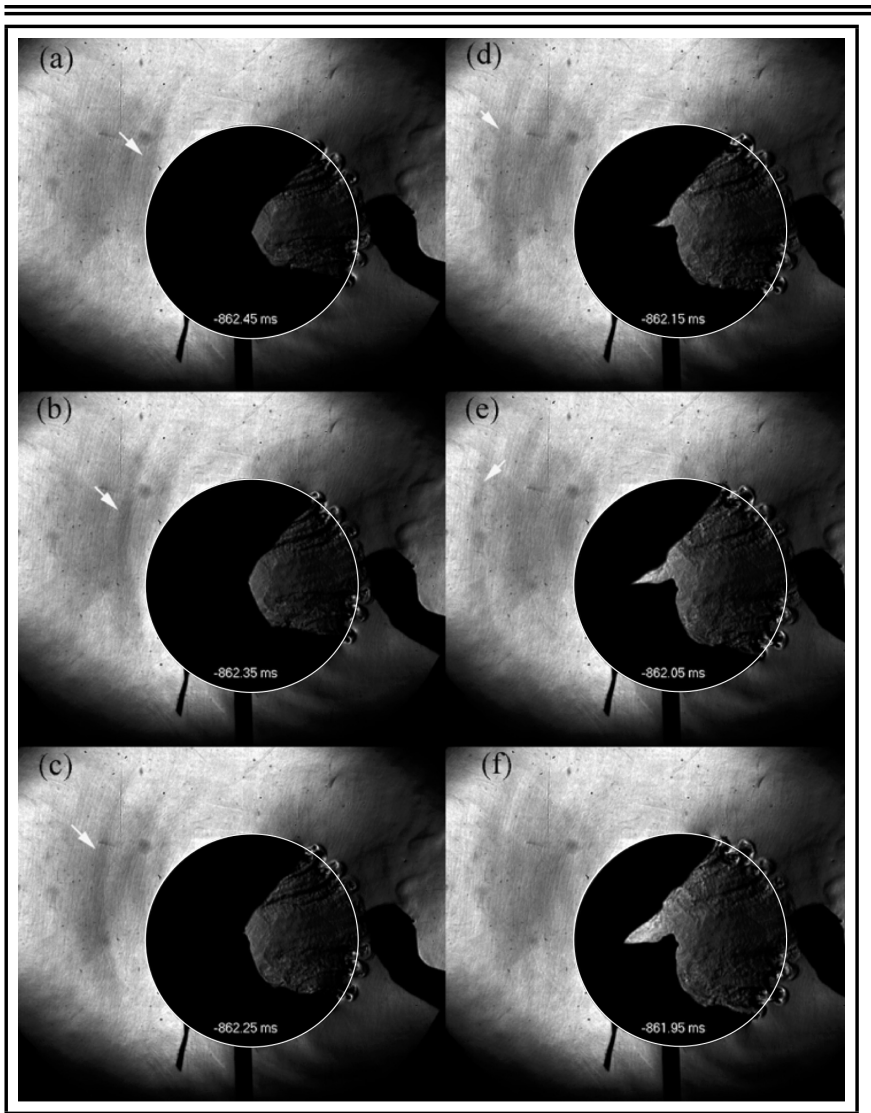

Figure 8. A second sequence of shadowgraph images of a round air-filled balloon, from the high-speed shadowgraph video with time intervals of $0.1 \mathrm{~ms}$ and increased contrast to highlight the emanating sound waves. The arrows mark an acoustic wave front.

ing from the intact balloon skin, far from the expanding breach.

The white arrow in figure 8(a) shows a large compression front attached to the intact skin, which propagates away in the subsequent frames. A closer look into the bottom lip of the ruptured skin in figures $8(\mathrm{a})$ and $8(\mathrm{e})$ shows germination of two consecutive compression fronts. The time difference between the two figures is $0.4 \mathrm{~ms}$, which corresponds to a frequency of $2500 \mathrm{~Hz}$, close to the spectral peaks shown earlier and within the uncertainty of the visual analysis of the video.

It's now worth evaluating the different hypotheses of noise generation proposed by the earlier researchers. An important observation from the shadowgraph images of Figure 7 is the absence of any shockwaves emanating from the flapping edge of the tear, which debunks the theory of noise generation due to the high-speed snapping of the free edge. An analysis of the video frames shows that the edge of the latex receding from the point of rupture moves at $\sim 100 \mathrm{~m} / \mathrm{s}$, so the latex does not move faster than the speed of sound. ${ }^{2}$ The time trace of Figure 2 shows that production time for the primary part of the sound burst occurs in less than $10 \mathrm{~ms}$. The shadowgraph images of Figure 7 indicate that compressed air mass within the balloon expands very little during that time. There is also no evidence of compression waves emanating from the expanding gas at the breach in the latex. Therefore, the hypothesis of excessive expansion of the gas to the point of overshooting and then air rushing back to fill the lower air pressure of reference ${ }^{1}$ also appears to be incorrect. The expansion of the compressed gas is also too slow to create sound waves. ${ }^{1,2}$ A separate analysis of the shadowgraph video shows that the latex recedes from the point of rupture at $\sim 100 \mathrm{~m} / \mathrm{s}$, so the latex does not move faster than the speed of sound, as suggested by Marder et al. ${ }^{2}$

The shadowgraph images of Figure 8 point towards the balloon skin as the source of noise generation as suggested by Barbut. $^{3}$ The gas under pressure creates tension in the latex skin and popping the balloon causes the stretched skin to vibrate like a drum. The vibrations take time to build up as the gas escapes. As the ripped latex retracts and the vibrating surface shrinks, the $\sim 3 \mathrm{kHz}$ oscillations produce less sound. The vibrations of the latex surface are accentuated at the torn edges, which radiate noise as the balloon collapses. Ripples form across the length of the edge, increasing noise radiation. The natural frequency of the balloon surface depends on the properties of the balloon itself, not on the gas filling the balloon.

Mouline and Abba-Bedia ${ }^{7}$ recently showed that balloons inflated above a pressure corresponding to a tensile stress of $88 \mathrm{MPa}$ fractured into multiple pieces when popped. Highspeed video of the bursting showed that the fractures in the latex were relatively evenly spaced which may be related to the vibration that resulted in the $\sim 3 \mathrm{kHz}$ frequency we saw in the noise generated by our balloons. They go on to note that the number of fractures increases with the tension in the latex. This may indicate that balloons made of varying thickness of latex may show different peak frequencies related to the natural frequency of the balloon surface. Further testing would be required to examine this hypothesis.

Another aspect of our results and those of Pätynen, et $\mathrm{al}^{4}$ is that the peak frequency does not change much with balloon diameter or shape. The animal balloons showed nearly the same peak frequency as various round balloons. This is likely due to the relatively constant tension in the membrane for the diameters in the various tests, which may keep the natural frequency of the membrane relatively constant with inflation diameter.

We have established that the most-likely noise-generating mechanism is the vibration of the free edges and the intact surface of the latex. Now turning to the observation of varying loudness with different inflation gas, we find that the explanation may be due to the energy stored in the compressed gas. The energy stored in a gas, $\mathrm{W}$, at an initial pressure of $P_{1}$ and an initial volume of $V_{1}$, and then compressed to a final pressure $P_{2}$ and volume $V_{2}$, can be expressed as: ${ }^{14}$

$$
W=\frac{P_{2} V_{2}-P_{1} V_{1}}{\gamma-1} .
$$

We assume that the compression process was performed isothermally, i.e. without an increase in temperature. The balloons were inflated slowly and the pressure inside was typically $4000 \mathrm{~Pa}$ (see Fig. 6) above atmospheric. Therefore, the temperature rise is expected to be small. Moreover, the heat is expected to be completely dissipated through the large surface. The balloons were inflated from zero volume, i.e. $V_{1}=0$, and they were all compressed to the same final volume $V_{2}$. Moreover, pressure $P_{2}$ inside all balloons of the same shape and inflation diameter was approximately the same (since the latex was stretched by the same amount). Therefore, the energy stored was inversely proportional to $(\gamma-1): W=$ $P_{2} V_{2} /(\gamma-1)$.

Table 3 shows the expected sound-level increments relative to helium that would result from the changes in density and ratio of specific heat for air and R-134A. The ratio of energy stored by air and $\mathrm{R}-134 \mathrm{~A}$ relative to that stored by helium are 
Table 3. Comparison of density and energy models of noise production with measured SPL differences.

\begin{tabular}{|c|c|c|c|c|c|}
\hline Gas & $\begin{array}{c}\text { Density, } \\
\mathrm{kg} / \mathrm{m}^{3}\end{array}$ & $\begin{array}{c}\text { Ratio of } \\
\text { Specific } \\
\text { Heats, } \gamma\end{array}$ & $\begin{array}{c}\text { SPL relative } \\
\text { to He: } \\
\text { proportional } \\
\text { to density, } \\
\mathrm{dB}\end{array}$ & $\begin{array}{c}\text { SPL relative } \\
\text { to He: } \\
\text { proportional } \\
\text { to } 1 /(\gamma-1), \\
\mathrm{dB}\end{array}$ & $\begin{array}{c}\text { Measured } \\
\text { SPL relative } \\
\text { to He for } \\
\text { fully-inflated } \\
\text { round } \\
\text { baloons, } \mathrm{dBA}\end{array}$ \\
\hline \hline Helium & 0.18 & 1.6 & 0 & 0 & 0 \\
\hline Air & 1.23 & 1.4 & 16.7 & 3.5 & 3 \\
\hline R-134A & 4.25 & 1.1 & 27.5 & 15.6 & 12 \\
\hline
\end{tabular}

2.5 and 6, respectively. Upon popping, balloons with higher stored energy are expected to create larger amplitude motion of the latex surface. This explains why the R-134A balloons usually created the loudest noise while the helium balloons created the weakest.

Based on the above energy content model, the expected increase in SPL for air-and-R-134A inflated balloons relative to helium balloons would be $3.5 \mathrm{dBA}$ and $15.6 \mathrm{dBA}$ respectively. For the fully inflated round balloons (Table 3), the air-filled balloons were $\sim 3 \mathrm{dBA}$ louder than helium filled balloons and the R-134A filled balloons were $\sim 12 \mathrm{dBA}$ louder, in line with this expectation. In contrast, using density to compute the expected changes in SPL results in large over-prediction of the SPL increases for air and R134A. The long and animal balloons behaved somewhat differently, depending on the level of inflation. For the partially filled long balloons, the different gases produced nearly the same sound levels although the $\mathrm{R}-134 \mathrm{~A}$ balloons were considerably louder above $3 \mathrm{kHz}$. The more fully inflated, animal balloons more closely followed the energy trends seen for the fully inflated round balloons.

\section{CONCLUSIONS}

The source of the noise generated by a popping balloon has been ascribed to a variety of causes. In this study, analysis of the sound characteristics of a large number of balloon pops showed that the measured waveform contradicts the two most popular hypotheses - that the sound is either an impulsive noise created by the sudden release of the gas from inside the balloon or is created by rapid snapping motion of the ripped edges of the latex membrane (akin to a cracking whip). The data presented here suggest a different mechanism, vibration of the balloon surface at its natural frequency initiated by the rupture of the latex and the subsequent release of the inflation gas. This hypothesis is supported by spectral analysis of the radiated noise and by a limited number of high-speed shadowgraph videos. Additionally, it is shown that the loudness of popped balloons is related to the energy stored in the gas during inflation - the higher the energy, the louder the pop.

\section{REFERENCES}

1 Murphy P. and Doherty, P., Not with a Whimper But a Bang, 1/22/13. Retrieved from http://www.sfsite.com/fsf/2009/pmpd0904.htm (Accessed February 15 2016)

2 Marder, M.P., Deegan, R.D., and Sharon, E. Crumpling, Buckling, and Crackling: Elasticity of Thin Sheets, Crumpling, Buckling, and Cracking: Elasticity of Thin Sheets, Physics Today, 60(33), (2007). https://dx.doi.org/10.1063/1.2711634
3 Barbut, O. When a balloon pops, what are the principles behind the popping sound? Is it the quick change in air pressure?, 1/22/13. Retrieved from http://www.quora.com/When-a-balloon-pops-what-arethe-principles-behind-the-popping-sound (Accessed February 15 2016)

4 Pätynen, J., Katz, B.F.G., and Lokki, T. Investigations on the balloon as an impulse source, J. Acoust. Soc. Am., 129(EL27), (2011). https://dx.doi.org/10.1121/1.3518780 (Accessed February 15 2016)

5 Horvat, M., Jambrosic, K., and Domitrovic, H. A Comparison of Impulse-Like Sources to be Used in Reverberation Time Measurements, Proceedings of the Acoustics'08, Paris, France (June 29 to July 4, 2008), 4503-4508. Retrieved from http://webistem.com/acoustics2008/acoustics2008/cd1/ data/articles/001865.pdf (Accessed February 15 2016)

6 Chéenne, D.J., Ardila, M., Lee, C.G., and Bridgewater, B. A Qualitative and Quantitative Analysis of Impulse Responses from Balloon Bursts, Journal of the Acoustical Society of America, 123, (2008).

7 Moulinet, S. and Adda-Bedia, M., Popping Balloons: A Case Study of Dynamical Fragmentation, Physical Review Letters, 115(30), (2015).

8 http://www.grc.nasa.gov/WWW/K-

12/airplane/airprop.html (Accessed February 15 2016), Air Properties Definition.

9 Helmenstine, A.M. Helium Facts Chemical \& Physical Properties of Helium. http://chemistry.about.com/od/elementfacts/a/helium.htm (Accessed February 15 2016)

10 Material Safety Data Sheet, Office Depot Cleaning Duster. Retrieved from http://kernair.org/Documents/MSDS/office\%20depot $\%$ 20cleaning\%20duster.pdf (Accessed February 15 2016)

11 Audacity ${ }^{\circledR}$ software is copyright(C) 1999-2014 Audacity Team. The name AudacityB is a registered trademark of Dominic Mazzoni.

12 Beck, S., Nakasone, H., and Marr, K. An Introduction to Forensic Gunshot Acoustics, ASA Lay Language Papers, 162nd Acoustical Society of America Meeting, (2011).

13 Jonas da Silva, M., Sanches, A., Malmonge, L., and Malmonge, J. Electrical, Mechanical, and Thermal Analysis of Natural Rubber/Polyaniline-Dbsa Composite, Ma. Res., 17(supl.1), Sao Carlos, Aug. (2014).

14 Van Wylen, G.J. and Sonntag, R.E. Fundamentals of Classical Thermodynamics, John Wiley and Sons, (1973). 